\title{
A New Expression for the Full Energy Photo-Peak Efficiency of a High Pure Germanium Detector as a Function of Distance and Energy
}

\section{Medhat ME*}

Experimental Nuclear Physics, Nuclear Research Centre, Atomic Energy Authority, Cairo, Egypt

\begin{abstract}
A new expression for the full energy photo-peak efficiency in terms of gamma ray energy and the sourcedetector distance has been obtained for a high pure germanium detector (HPGe) using different standard sources. Comparison of the calculated efficiencies and the experimentally measured values for the energy range from 59.51332.2 KeV and a source-detector distances 5, 10, 15, 20, 25 and $30 \mathrm{~cm}$. This shows a good agreement between the theory and the experiment.
\end{abstract}

Keywords: Energy; Gamma ray; Geometry; Germanium detector

\section{Introduction}

In the field of neutron activation analysis and gamma spectroscopy need the accurate knowledge of the efficiency of the detection system for the source-detector geometry. There are two ways for this geometry; (1) The fixed Source-detector geometry and (2) the variable sourcedetector geometry. In case of fixed Source detector geometry, the efficiency (eff) depends only on the gamma ray energy (E) but in case of variable source detector geometry it depends not only the energy of the gamma ray line but also the distance between the source and the detector. Thus by using the fixed source-detector geometry approach, experimental measurements were made at different source-detector distances. The measured efficiencies are plotted on the same graph and a family of curves is obtained, each curve represents a different distance from the detector surface. Measurements were made using a high pure germanium detector system at the laboratory of neutron generator in nuclear research centre, Egypt.

\section{Theory}

The full energy peak efficiency (eff) of a high pure germanium (HPGe) detector may be expressed in the form of a polynomial with respect to the gamma-ray energy $(\mathrm{E})$ as $[1,2]$ :

$$
\ln (\text { eff })=\sum_{i=0}^{n} k(\ln (E))^{i}
$$

Where $\mathrm{k}_{\mathrm{i}}$ are the coefficients of the polynomial and are different at source-to-detector distance, $\mathrm{d}$.

These coefficients, $\mathrm{k}$, may be obtained for each distance by fitting Eq.(1) to the experimental measured efficiency values for that particular, d, distance.

Assuming the coefficients, $\mathrm{k}_{\mathrm{i}}$ can be expressed in a polynomial form involving, $d$, then we may write:

$$
\underset{i}{k}=\sum_{j=0}^{m} k d^{j}
$$

where $K_{i j}$ are the coefficients of the polynomial. These coefficients, $K_{i j}$, may also be obtained by fitting the graphs of $\mathrm{k}_{\mathrm{i}}$ versus distances (d) with Eq 2. Thus by combining Eq (1) and Eq (2) a general equation for the efficiency may be expressed as:

$$
\ln (\text { eff })=\sum_{i=0}^{n} \sum_{j=0}^{m} k d^{j}(\ln (E))^{i}
$$

Hence knowing the constants, $\mathrm{K}_{\mathrm{ii}}$, the full energy peak efficiency may be obtained for a wide range of gamma-ray energies and for a various distances from the source to detector. Experimentally, the full energy peak efficiency for a particular sample-to detector geometry is obtained by measuring the net counts under the photopeak energy of interest and using the formula:

$$
e f f=\frac{N(E)}{A_{s t d} I_{r}(E) C_{A B S} C_{S E A}}
$$

where $\mathrm{N}(\mathrm{E})$ is the net activity (count/second) under the photo peak, $\mathrm{A}_{\text {std }}$ is the activity of the standard source, $\mathrm{I}_{\mathrm{r}}(\mathrm{E})$ is the emission probability per decay for the particular gamma transition, $\mathrm{C}_{\mathrm{ABS}}$ and $\mathrm{C}_{\mathrm{SEA}}$ are the respective correction factors for self -absorption and summing effect.

\section{Experimental}

The gamma ray counting system consists of high pure germanium detector with relative efficiency $25 \%$ and an energy resolution of 1.9 $\mathrm{KeV}$ at $1332.5 \mathrm{KeV}$ of $\mathrm{Co}^{60}$ standard sources. The detector was housed in a lead cylinder of thickness $5 \mathrm{~cm}$ to reduce the effect of the back ground as low as possible. The other associated electronics consisted of an H.V model ORTEC 660 and an amplifier of type TC-243 TENNELEC. The electronics was configured to observe gamma rays in the range $\sim 30$ to $2000 \mathrm{KeV}$. Pulse computer analyzer (PCAIII) card is used in the measurements. Point standard sources of known activities, supplied by the International Atomic Energy Authority (IAEA), provided the necessary gamma-ray energies for the measurement. The specification of these sources is given in Table 1 . The sources were placed at different distances from the surface of the detector such that the vertical axis through the centre of the source and normal to the plane of the source coincided with that of the detector. The sources were counted for 2000 second at distances 5, 10,15, 20,25, $30 \mathrm{~cm}$. By using Eq (4) the full energy peak efficiency values were calculated and are displayed as dots.

*Corresponding author: Medhat ME, Experimental Nuclear Physics, Nuclea Research Centre, Atomic Energy Authority, Cairo, Egypt, Tel: +8618266769532; E-mail: medhatme@ymail.com

Received May 13, 2015; Accepted June 19, 2015; Published June 26, 2015

Citation: Medhat ME (2015) A New Expression for the Full Energy Photo-Peak Efficiency of a High Pure Germanium Detector as a Function of Distance and Energy. J Appl Mech Eng 4: 168. doi:10.4172/2168-9873.1000168

Copyright: (c) 2015 Medhat ME. This is an open-access article distributed unde the terms of the Creative Commons Attribution License, which permits unrestricted use, distribution, and reproduction in any medium, provided the original author and source are credited. 
Citation: Medhat ME (2015) A New Expression for the Full Energy Photo-Peak Efficiency of a High Pure Germanium Detector as a Function of Distance and Energy. J Appl Mech Eng 4: 168. doi:10.4172/2168-9873.1000168

Page 2 of 3

\begin{tabular}{|c|c|c|c|c|c|}
\hline Standard Source & Energy (KeV) & Branching ratio \% & Half-life & Activity $\mathbf{m ~ C i}$ & Date of calibration \\
\hline $\mathrm{Am}^{241}$ & 59.5 & 35.7 & $432.21 \mathrm{y}$ & 10 & $5-25-1994$ \\
\hline $\mathrm{Co}^{57}$ & 122.1 & 85.2 & $270.0 \mathrm{~d}$ & 2.33 & 4-26-1995 \\
\hline \multirow[t]{2}{*}{$\mathrm{Ba}^{133}$} & 356 & 62.1 & $10.7 y$ & 0.77 & \multirow[t]{2}{*}{ 10-3-1994 } \\
\hline & 81 & 33.8 & $10.7 y$ & 0.77 & \\
\hline $\mathrm{Cs}^{137}$ & 661.7 & 85.21 & 30.17 y & 0.88 & $1-17-95$ \\
\hline $\mathrm{Mn}^{54}$ & 834.8 & 99.98 & 312.12 & 1.53 & $5-2-95$ \\
\hline \multirow[t]{2}{*}{$\mathrm{Co}^{60}$} & 1173.2 & 99.9 & 5.27 & 0.98 & \multirow[t]{2}{*}{$10-4-94$} \\
\hline & 1332.5 & 99.98 & 5.27 & 0.98 & \\
\hline $\mathrm{Na}^{24}$ & 1275.5 & 100 & $2.6 \mathrm{y}$ & 0.93 & $10-3-94$ \\
\hline
\end{tabular}

Table 1: Specification of the IAEA used for the efficiency measurements.

\begin{tabular}{|c|c|c|c|c|c|}
\hline \multirow{3}{*}{$\begin{array}{l}\text { Sample To Detector } \\
\text { Distance (d), cm }\end{array}$} & \multicolumn{5}{|c|}{ Coefficients of energy Polynomial $k_{i}$} \\
\hline & \multicolumn{3}{|c|}{$\mathrm{E} \leq 356 \mathrm{KeV}$} & \multicolumn{2}{|c|}{$\mathrm{E}>356 \mathrm{KeV}$} \\
\hline & $\mathrm{K}_{0} \times 10^{-2}$ & $k_{1} \times 10^{-4}$ & $k_{2} \times 10^{-7}$ & $\mathbf{k}_{0}$ & $\mathbf{k}_{1}$ \\
\hline 5 & 15.14 & -2.23 & -1.82 & 14.05 & -2.9 \\
\hline 10 & 10.27 & -4.33 & 5.81 & 11.38 & -2.58 \\
\hline 15 & 4.98 & -1.91 & 5.81 & 7.14 & -2.02 \\
\hline 20 & 1.24 & 0.12 & -1.03 & 4.83 & -1.76 \\
\hline 25 & 0.68 & 0.12 & -0.67 & 3.89 & -1.67 \\
\hline 30 & 0.41 & 0.12 & -0.6 & 3.44 & -1.65 \\
\hline
\end{tabular}

Table 2: Coefficients of energy polynomial $\mathrm{K}_{\mathrm{i}}$.

\begin{tabular}{|c|c|c|c|c|c|}
\hline \multirow{2}{*}{$\begin{array}{c}\text { Coefficients of energy } \\
\text { Polynomial }\end{array}$} & \multicolumn{5}{|c|}{ Coefficients of the d Polynomial $k_{i j}, E \leq 356 \mathrm{KeV}$} \\
\hline & $\mathrm{k}_{\mathrm{io}}$ & $\mathrm{k}_{\mathrm{i} 1}$ & $\mathrm{ki}_{2}$ & $\mathrm{ki}_{3}$ & $\mathrm{ki}_{4}$ \\
\hline $\mathrm{k}_{0}$ & 0.138 & 0.013 & $-0.002 \times 10^{-2}$ & $1.192 \times 10^{-4}$ & $-1.615 \times 10^{-6}$ \\
\hline $\mathrm{k}_{1}$ & 0.001 & $-4.952 \times 10^{-4}$ & $-7.93 \times 10^{-8}$ & $2.518 \times 10^{-9}$ & $-2.763 \times 10^{-11}$ \\
\hline $\mathrm{k}_{2}$ & $-3.363 \times 10^{-6}$ & $9.707 \times 10^{-7}$ & $-7.935 \times 10^{-8}$ & $2.518 \times 10^{-9}$ & $-2.763 \times 10^{-11}$ \\
\hline $\begin{array}{c}\text { Coefficients of energy } \\
\text { Polynomial }\end{array}$ & \multicolumn{5}{|c|}{ Coefficients of the d- Polynomial $k_{i j}, E>356$} \\
\hline $\mathrm{k}_{\mathrm{i}}$ & $\mathrm{k}_{\mathrm{io}}$ & $\mathrm{k}_{\mathrm{i} 1}$ & $\mathrm{ki}_{2}$ & $\mathrm{ki}_{3}$ & $\mathrm{ki}_{4}$ \\
\hline $\mathrm{k}_{0}$ & 10.65934 & 1.73261 & -0.26124 & 0.01092 & $-1.47 \mathrm{E}-04$ \\
\hline $\mathrm{k}_{1}$ & -2.36215 & -0.26062 & 0.0376 & -0.00158 & 2.13E-05 \\
\hline
\end{tabular}

Table 3: Coefficients of $k_{i j}$, corresponding to each of the energy coefficient $k_{1}$.

\section{Results}

\section{Determination of the coefficients, $K_{1}$}

To obtain the coefficients $\mathrm{K}_{\mathrm{i}}$, the experimental measured efficiency for the different d-position were fitted with theoretical functions. Since it was not possible to cover the full energy range of $59.5-1332.2 \mathrm{KeV}$ with a single polynomial, the range was divided into two portions, a lower energy portion with $\mathrm{E} \leq 356 \mathrm{KeV}$ and a higher energy portion with $\mathrm{E}>356 \mathrm{KeV}$. A theoretical fit was then applied to each portion separately. For the lower energy portion a second order polynomial in E could fit the experimental data:

$$
\text { eff }=\sum_{i=0}^{2} k_{i} E^{i}
$$

where $k_{i}$ are the coefficients of the polynomial. For the higher energy portion a first order polynomial in $\ln (\mathrm{eff})$ was used to fit the experimental data,

$$
\ln (e f f)=k_{0}+k_{1} \ln (E)
$$

$\mathrm{k}_{\mathrm{i}}$ values are obtained from the fit of the different(d) positions are shown in Table 2.

\section{Determination of the coefficients $\mathbf{k}_{\mathrm{ij}}$}

To obtain the coefficients, $\mathrm{K}_{\mathrm{ij}}$, graphs of the coefficients $\mathrm{k}_{\mathrm{i}}$ versus $\mathrm{d}$, for the two separated portions. The results of the fit showed that showed that for the two portions a fourth order polynomial function in terms of $d$ could fit the data: i.e.:

$$
k_{i}=\sum_{j=0}^{4} k_{i j} d^{j}
$$

The values of the coefficients, $\mathrm{K}_{\mathrm{ij}}$ are shown in Table 3, Efficiency as a function of distance and energy

From the theoretical fit to the experimental data, the following expression was for the efficiency of the detector from the energy of 59.5 $\leq \mathrm{E} \leq 1332.2 \mathrm{KeV}$ and for a source to detector distance of the range of $5 \leq \mathrm{d} \leq 30$ :

$$
\text { eff }=\sum_{i=0}^{1} \sum_{j=0}^{4} k d^{j} E^{i} \quad \text { For } \mathrm{E} \leq 356 \mathrm{KeV}
$$

and, $\ln (e f f)=\sum_{j=0}^{4} k_{0 j} d^{j}+\left(\sum_{j=0}^{4} k_{1 j} d^{j}\right.$ For E $>356 \mathrm{KeV}$ 
Citation: Medhat ME (2015) A New Expression for the Full Energy Photo-Peak Efficiency of a High Pure Germanium Detector as a Function of Distance and Energy. J Appl Mech Eng 4: 168. doi:10.4172/2168-9873.1000168

Page 3 of 3

\begin{tabular}{|c|c|c|c|c|c|c|}
\hline \multicolumn{7}{|c|}{ Detector efficiency $\left(\mathrm{eff} \times 1^{-2}\right)$} \\
\hline $\begin{array}{c}\text { Energy } \\
(\mathrm{KeV})\end{array}$ & $\begin{array}{c}\text { Exp. } \\
\mathrm{d}=5 \mathrm{~cm}\end{array}$ & Calc. & devation, $\%$ & $\begin{array}{c}\text { Exp. } \\
\mathrm{d}=10 \mathrm{~cm}\end{array}$ & Calc. & devation, $\%$ \\
\hline 59.5 & 13.590 & 13.756 & 1.221486 & 7.653 & 7.902 & 3.24 \\
\hline 81.0 & 13.790 & 13.223 & -0.04112 & 7.559 & 7.151 & -5.44 \\
\hline 122.1 & 11.920 & 12.155 & 0.019715 & 5.687 & 5.853 & 2.92 \\
\hline 356.0 & 4.895 & 4.852 & -0.00878 & 2.229 & 2.249 & 0.89 \\
\hline 661.7 & 0.818 & 0.800 & -0.022 & 0.475 & 0.453 & -4.58 \\
\hline 834.8 & 0.390 & 0.407 & 0.04359 & 0.244 & 0.248 & 1.84 \\
\hline 1173.2 & 0.144 & 0.151 & 0.048611 & 0.0991 & 0.1032 & 4.17 \\
\hline 1275.5 & 0.1200 & 0.1189 & -0.00917 & 0.0827 & 0.0831 & 0.47 \\
\hline 1332.5 & 0.1300 & 0.1247 & -0.04077 & 0.0773 & 0.0742 & -4.05 \\
\hline \multicolumn{7}{|c|}{ Detector efficiency (eff $\times 10^{-2}$ ) } \\
\hline $\begin{array}{c}\text { Energy } \\
(\mathrm{KeV})\end{array}$ & $\begin{array}{c}\text { Exp. } \\
\mathrm{d}=15 \mathrm{~cm}\end{array}$ & Calc. & devation, $\%$ & $\begin{array}{c}\text { Exp. } \\
\mathrm{d}=20 \mathrm{~cm}\end{array}$ & Calc. & devation, $\%$ \\
\hline 59.5 & 3.754 & 3.915 & 4.28 & 1.188 & 1.144 & -3.72 \\
\hline 81.0 & 3.833 & 3.567 & -6.94 & 1.438 & 1.379 & -4.08 \\
\hline 122.1 & 2.848 & 2.955 & 3.77 & 1.18 & 1.244 & 5.42 \\
\hline 356.0 & 0.828 & 0.848 & 2.41 & 0.385 & 0.400 & 4.10 \\
\hline 661.7 & $0 . .262$ & 0.241 & -7.93 & 0.147 & 0.144 & -1.76 \\
\hline 834,8 & 0.1450 & 0.1505 & 3.79 & 0.0893 & 0.0892 & -0.12 \\
\hline 1173.2 & 0.0735 & 0.0755 & 2.74 & 0.0459 & 0.0450 & -2.06 \\
\hline 1275.5 & 0.0629 & 0.0637 & 1.31 & 0.0418 & 0.0423 & 1.08 \\
\hline 1332.5 & 0.0618 & 0.0583 & -5.71 & 0.0401 & 0.0391 & -2.60 \\
\hline \multicolumn{7}{|c|}{ Detector efficiency (eff $\left.\times 10^{-2}\right)$} \\
\hline $\begin{array}{c}\text { Energy } \\
(\mathrm{KeV})\end{array}$ & $\begin{array}{c}\text { Exp. } \\
\mathrm{d}=25 \mathrm{~cm}\end{array}$ & Calc. & devation, $\%$ & $\begin{array}{c}\text { Exp. } \\
\mathrm{d}=30 \mathrm{~cm}\end{array}$ & Calc. & devation, $\%$ \\
\hline 59.5 & 0.688 & 0.663 & -3.50 & 0.463 & 0.485 & 4.83 \\
\hline 81.0 & 0.814 & 0.839 & 3.132 & 0.536 & 0.500 & -6.69 \\
\hline 122.1 & 0.702 & 0.733 & 4.415 & 0.498 & 0.512 & 2.95 \\
\hline 356.0 & 0.265 & 0.261 & -1.24 & 0.192 & 0.188 & -1.61 \\
\hline 661.7 & 0.0927 & 0.0926 & -0.12 & 0.0660 & 0.0678 & 1.95 \\
\hline 834.8 & 0.0609 & 0.0627 & 2.88 & 0.0453 & 0.0462 & 2.02 \\
\hline 1173.2 & 0.0347 & 0.0355 & 2.26 & 0.0262 & 0.0263 & 0.49 \\
\hline 1275.5 & 0.0317 & 0.0308 & -2.78 & 0.0232 & 0.0229 & -1.29 \\
\hline 1332.5 & 0.0290 & 0.0287 & -1.03 & 0.0216 & 0.0213 & -1.47 \\
\hline
\end{tabular}

Table 4: Comparison of the experimental and calculated efficiencies.

So, a general analytical function was obtained for calculating the efficiency as a function of both distance and energy. Table 4 shows the experimental efficiencies and the values obtained using Eq (8). It can be seen that the calculated efficiencies agree very well with the experimental values.

\section{Conclusion}

The results of the measurements show that the efficiency of HPGe detector may be expressed as a function of both the gamma ray energy of the sample and the vertical distance from the detector surface .It is clear that this equation (Eq 8), the efficiency of the detector, at any position within the selected energy, $\mathrm{E}$ and the ranges obtained by calculation without any experimental measurements.

\section{References}

1. Nix DE, Scott NE (1976) Detection Efficiency Calibration for radiological Monitoring of Nuclear Plants Radioelement Analysis: Progress and Problems Proc of the $23^{\text {rd }}$ Conf on Analytical Chemistry in Energy and Technology Gatlinburg Tennessee.

2. Sanderson CG (1976) Comparison of Ge(Li) well and N-type Coaxial Detector for Low-Energy Gamma-Ray Analysis of Environment Samples Radioelement Analysis: Progress and Problems Proc 23 Conf on Analytical Chemistry in Energy and Technology Gatlinburg Tennessee. 